\title{
FEM AND EXPERIMENTAL ANALYSIS OF THIN-WALLED COMPOSITE ELEMENTS UNDER COMPRESSION
}

\author{
P. RÓŻYŁO*, P. WYSMULSKI and K. FALKOWICZ \\ Lublin University of Technology \\ Faculty of Mechanical Engineering \\ Department of Machine Design and Mechatronics \\ Nadbystrzycka 36, 20-618 Lublin. POLAND \\ E-mails: p.rozylo@pollub.pl; p.wysmulski@pollub.pl; k.falkowicz@pollub.pl
}

\begin{abstract}
Thin-walled steel elements in the form of openwork columns with variable geometrical parameters of holes were studied. The samples of thin-walled composite columns were modelled numerically. They were subjected to axial compression to examine their behavior in the critical and post-critical state. The numerical models were articulately supported on the upper and lower edges of the cross-section of the profiles. The numerical analysis was conducted only with respect to the non-linear stability of the structure. The FEM analysis was performed until the material achieved its yield stress. This was done to force the loss of stability by the structures. The numerical analysis was performed using the ABAQUS ${ }^{8}$ software. The numerical analysis was performed only for the elastic range to ensure the operating stability of the tested thin-walled structures.
\end{abstract}

Key words: thin-walled structures, finite element method, numerical and experimental investigations, buckling.

\section{Introduction}

The intensive development of industry requires constructors to use modern materials with enhanced performance properties. The main goal is to reduce the mass of elements while maintaining or improving their strength and stiffness. One group of load-carrying structures characterized by the above properties are thin-walled structures. Nonetheless, these structures have one disadvantage - they are prone to a loss of stability. Despite the occurrence of buckling and loss of stability, however, such structures can still operate. This phenomenon results from the fact that their behavior changes from linear to non-linear. The problem of stability of thin-walled structures under static loads was analyzed, among others, in the works: [[2], [9]-[14], [17], [18], [23]-[28], [32], [33]].

The literature on the problem of load-carrying capacity of thin-walled composite structures is limited; theoretical and numerical studies prevail, and there are few studies in which experimental results are reported. This paper investigates composite columns with widely used cross-sectional profiles. Two profiles are analyzed: one with a channel section and the other with an open top-hat crosssection, subjected to axial compressive load. The study was performed for the critical and weakly postcritical state to define the forces which cause the structure's loss of stability. There are many publications investigating the problem of critical state of thin-walled composite elements with respect to structure stability [[4]-[9], [19], [20], [25], [26], [30], [33]].

This study is a comparative analysis of the behavior of the tested structures observed in the numerical analysis and experimental tests. To this end, real boundary conditions of the profiles adequate to the assumptions of an ideal FEM model have been appropriately mapped. The key aspect was to determine the value of the critical force, which could only be done using some methods of approximation. There are many approximation methods which can be applied to determine the

\footnotetext{
* To whom correspondence should be addressed
} 
approximate value of critical load, starting from the oldest: the Southwell method [21], the Tereszowski method [29], to the more recent ones - the method of lines intersection [20], [34], tangent vertical [20], [34], inflection point [20], [34], $P$ - $w_{c}{ }^{2}$ and $P-w_{c}{ }^{3}$ [20], [34] and the Koiter method [20], [31]. The numerical analysis was performed for a linear eigenvalue problem using the minimum potential energy criterion to determine critical load, while the experimental tests involved the application of approximation methods. The final step of the analysis was to determine the convergence of the obtained results in the form of deflection state characteristics to loading of critical range. The main aim of this work was to determine the level of compatibility between numerical results and experimental findings for the process under investigation.

\section{Research object and methodology}

Thin-walled composite profiles with different cross-sectional shapes lengths were examined. The mechanical properties of the structures complied with the parameters of carbon composite M12/35\%/UD134/AS7. The thin-walled profiles were made of HexPly unidirectional carbon-epoxy composite prepregs. The main mechanical properties of the tested composite were: Young's modulus in fiber direction and perpendicular to the fibers, Poisson's ratio, shear strength, the Kirchhoff modulus and compressive strength in fiber direction and perpendicular to the fibers [4].

Table 1. Mechanical properties.

\begin{tabular}{|c|l|}
\hline $\mathrm{E}_{1}[\mathrm{MPa}]$ & 130710 \\
\hline $\mathrm{E}_{2}[\mathrm{MPa}]$ & 6360 \\
\hline $\mathrm{v}[-]$ & 0.32 \\
\hline $\mathrm{G}[\mathrm{MPa}]$ & 4180 \\
\hline$F_{c u}\left(0^{\circ}\right)[\mathrm{MPa}]$ & 1531 \\
\hline$F_{c u}\left(90^{\circ}\right)[\mathrm{MPa}]$ & 214 \\
\hline$F_{s u}[\mathrm{MPa}]$ & 100.15 \\
\hline
\end{tabular}

The experimentally determined mechanical properties of the composite enabled further defining of the model in order to perform numerical calculations. Such elements are widely used in the aerospace industry as shell plating strengthening in passenger aircraft. The application of the profiles with the selected geometry enables an effective reduction in the weight of the structure while, simultaneously, increasing its strength. This solution enables the reduction of stresses generated by longitudinal forces during the work of the whole structure. The study analyzed two different types of open cross section profiles made of the same composite material. Channel section and open top-hat section profiles are good examples of structures characterized by high stiffness. The analysis was performed for two types of structure: one was a C-shaped column, whereas the other was an open top-hat column with two additional edges of the cross section increasing its stiffness. The selected composite profiles exert a significant impact on the durability and strength of the compressed structure during operation. The real structures and schematic designs of their cross sections are shown in the figures below. 
a)
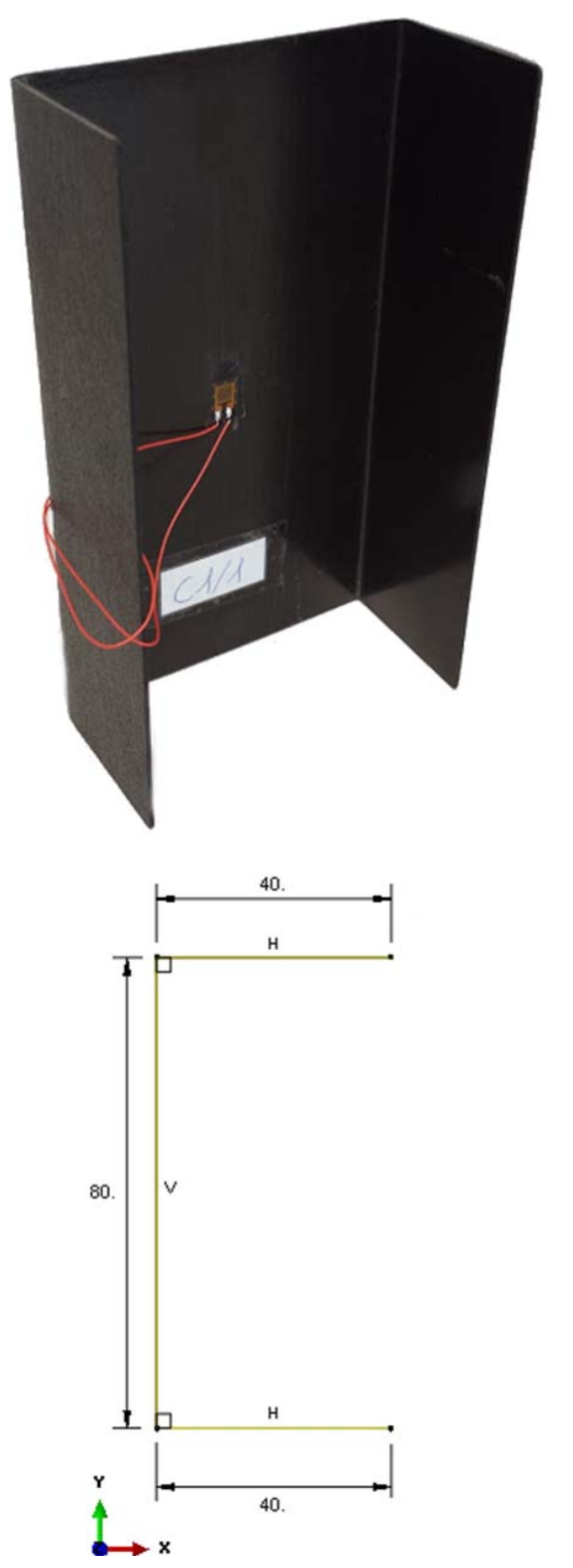

b)
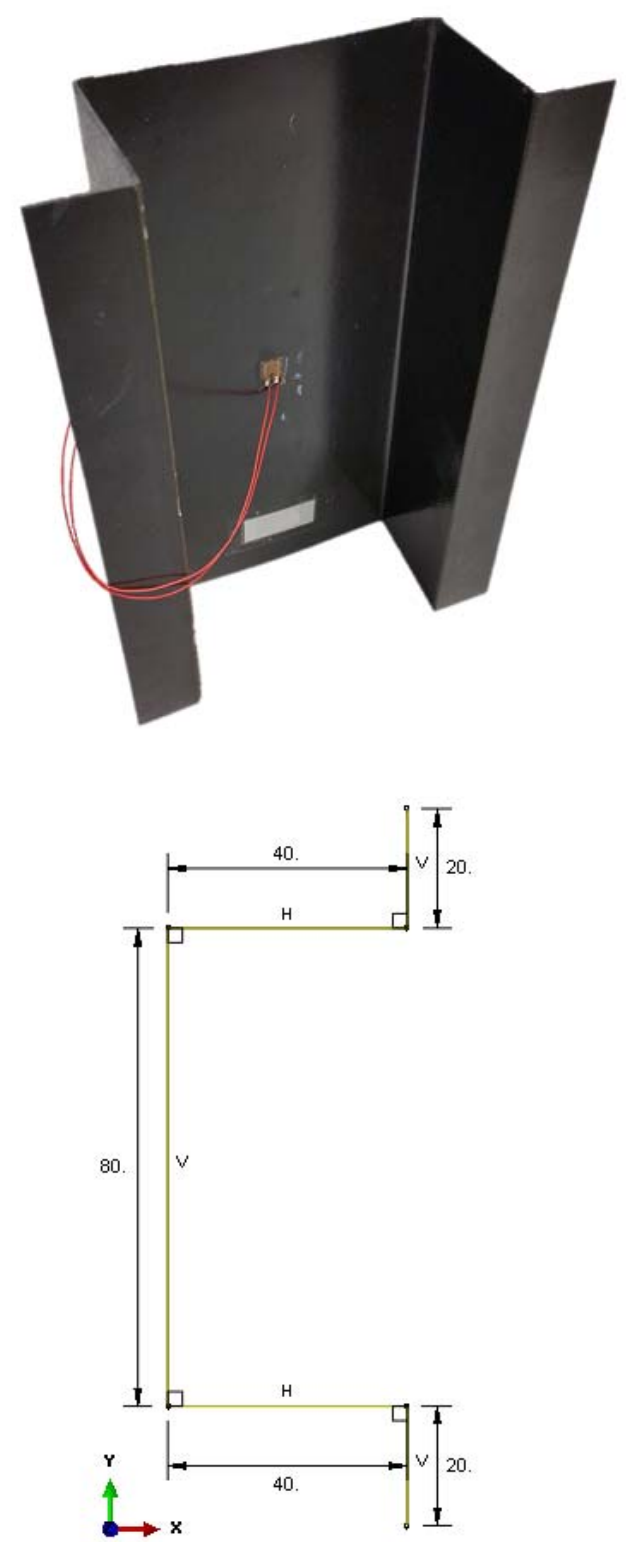

Fig.1. Real model and the parameters of cross-section:

a) sample of channel section, b) sample of open top-hat.

The thin-walled profiles were characterized by varied configurations of the composite layers. The thickness of a single layer in both structures was the same and was equal to $0.131 \mathrm{~mm}$. The composite consisted of 8 layers with different configurations of the laminate fibers relative to the central plane. The $\Omega$ shape section profile had the [0/90/0/90/90/0/90/0] layer configuration. The C-shape section column had the configuration described by [0/-45/45/90/90/45/-45/0]. The samples had fixed cross-sectional geometric parameters, as shown in Fig.1. They differed in terms of length - the $\Omega$-column was $180 \mathrm{~mm}$ while the Cshaped column was $143 \mathrm{~mm}$. In addition, the same FEM models of the two tested structures were made, and they were fully numerically mapped in the Abaqus program to enable the implementation of the finite element method in the study. 
The experimental analysis of the critical load in the weakly post-critical state was conducted under standard conditions using the Zwick Z100 universal testing machine with the maximum force of about $100 \mathrm{kN}$ and constant velocity of the cross-bar set to $2 \mathrm{~mm} / \mathrm{min}$. The precise mapping of the real boundary conditions complying with the ideal FEM assumption complied with the classical idea of articulated support. To ensure the accuracy of the boundary conditions in the experiments, appropriate heads with a flat working surface were applied alongside panel sleepers and plastic sleepers to ensure the correct position of the profiles during the compression process. The realization of the applied boundary conditions in the experimental tests is presented in Fig.2.

a)

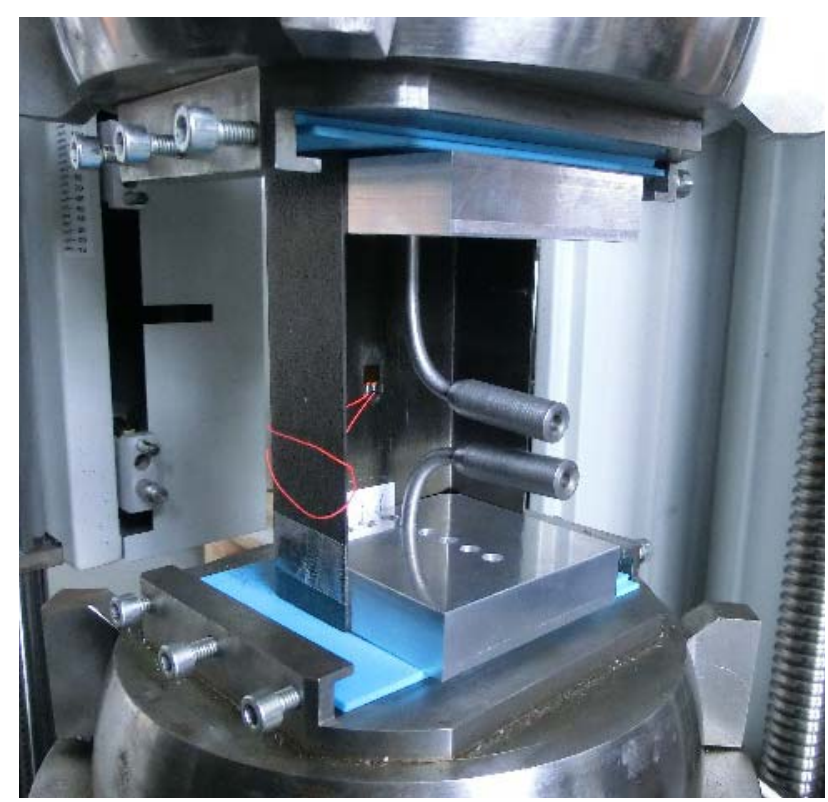

b)

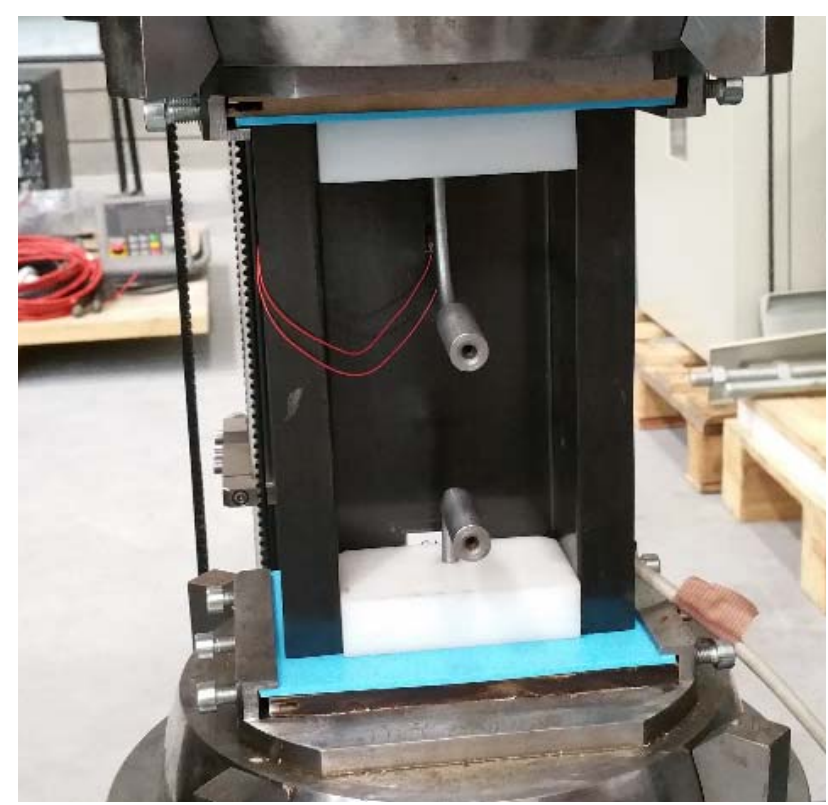

Fig.2. Boundary conditions: a) C-shape section sample, b) $\Omega$-shape section sample.

The full mapping of the boundary conditions in the FEM analysis was possible by assigning the compressive load to the upper end of the cross section and by blocking the degrees of freedom to reflect the real state. The essential part of the numerical study was to perform a correct numerical discretization of the model. The shell model was made of finite elements defined as S8R - i.e., shell elements described by the square shape function and reduced integration. The technique of reduced integration is one of the oldest techniques of approximation of the displacement-stress state in an element. Reduced integration allows us to remove the false modes of deformation of the finite elements by using a higher order polynomial function in the description of the element function [35]. The open top-hat section profile was assigned about 4000 mesh elements, while the channel section profile involved the use of 5700 elements. Below, you can see the numerical models after discretization and the boundary conditions applied. 
a)

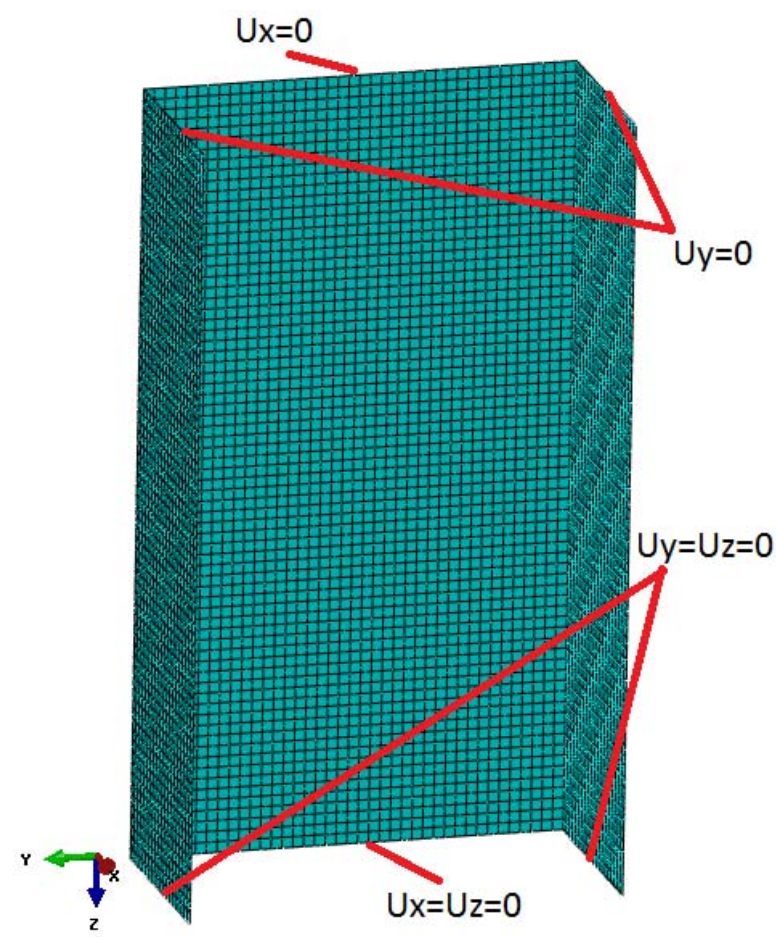

b)

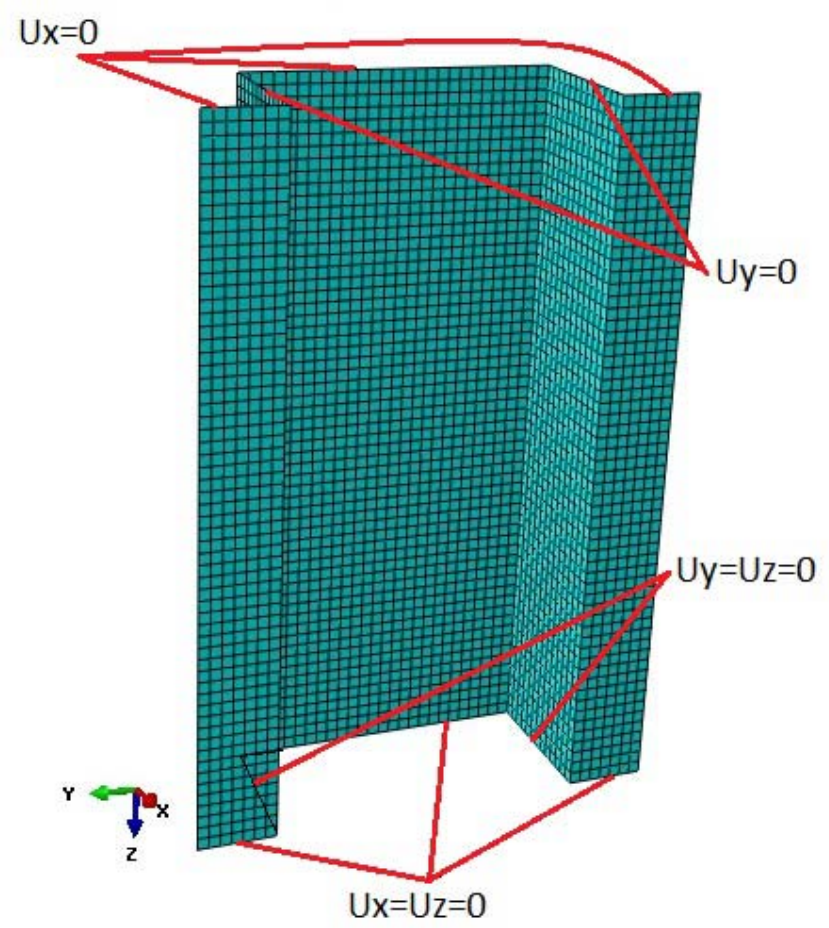

Fig.3. Numerical model with boundary conditions: a) C-shape profile, b) $\Omega$-shape profile.

\section{Results}

The experimental and numerical studies determined the values of critical forces during axial compression. In the numerical analysis, the determination of precise values of the critical forces involved solving a linear eigenvalue problem. This led to obtaining the criterion of minimum potential energy for the tested structures. In the experimental tests the critical forces could not be precisely determined based on the obtained characteristics of load and deformation. In order to obtain approximate values of the forces causing loss of stability, it was necessary to use approximation methods. In this study, the process of approximation involved describing the relationship between load and deformation in the form of specific functions according to the selected method of approximation [20]. With regard to the $\mathrm{C}$ and $\Omega$-shape section profiles, the approximate experimental value of the critical force was determined by the cubic Koiter method. The inflection point method allows us to determine buckling load by the best fitting of third-degree polynomial approximation of the results, as shown in the load vs. deflection chart. The selection criterion of the points is a value of the R-squared coefficient which must be higher than 0.99. The intersection of the approximation function with the vertical axis of the chart describing compressive load indicates the approximate value of the critical force. The process of experimental and numerical determination of the force, at which buckling occurs, showed a very high agreement of the numerical and experimental results. The figures below show the critical forces in the investigated cases obtained in the experiment conducted with the use of the testing machine. 


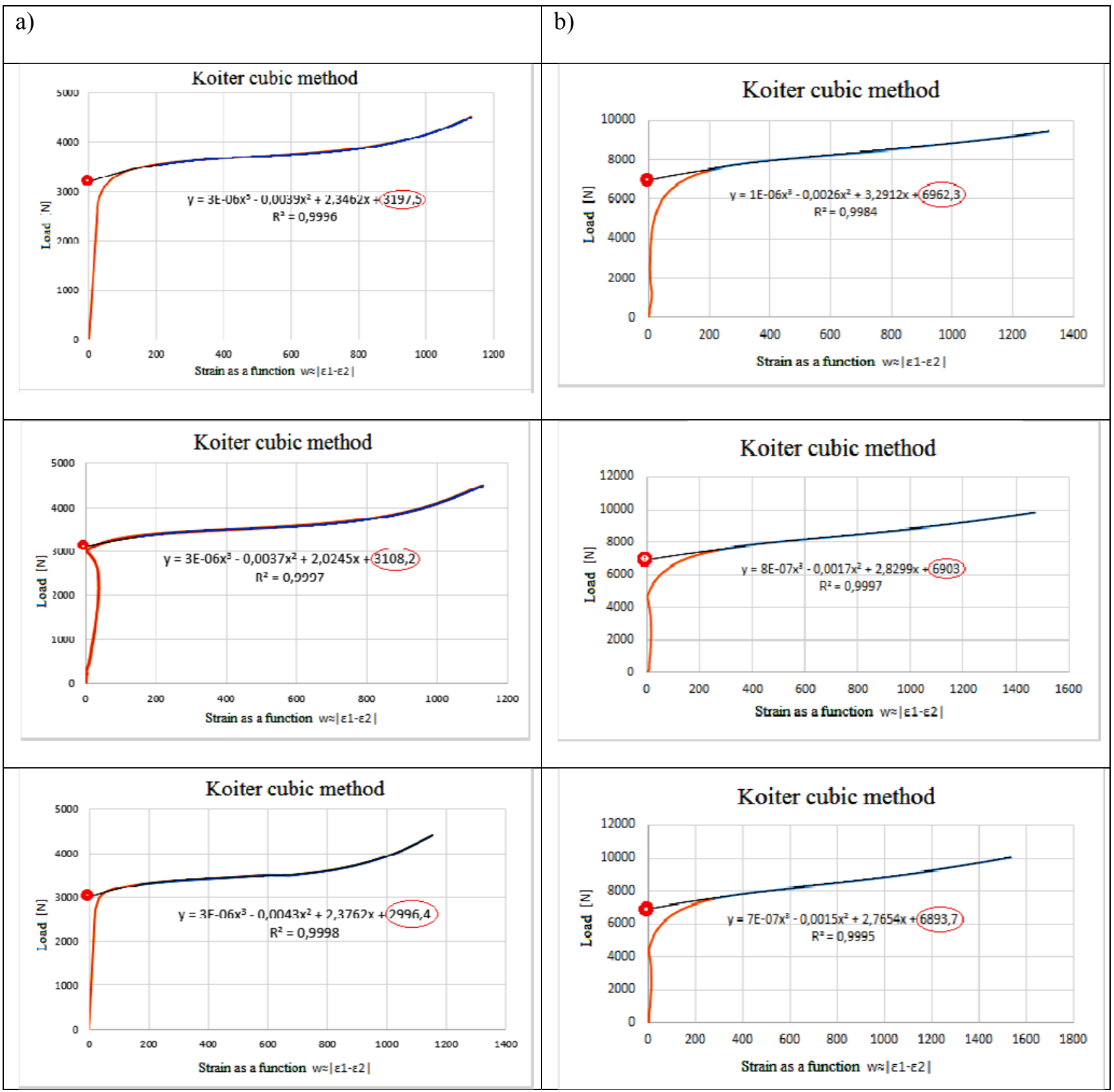

Fig.4. Experimental results of approximate critical forces:

a) results from three tests for the $\mathrm{C}$ shape profile, b) result from three tests for the $\Omega$ shape profile.

The determination of the critical state of the structure was based on determining the load value under which the structure's behavior changes to non-linear work. The application of the approximation method allowed us to determine the level of convergence between the experimental findings and the numerical results.

The approximation was done using the advanced Koiter method due to the fact that it is one of the most effective ways of determining the approximate values of critical loads for samples characterized by high stiffness. The critical forces defined by the advanced numerical analysis that involved solving an eigenvalue problem are shown in the figures below. 
a)

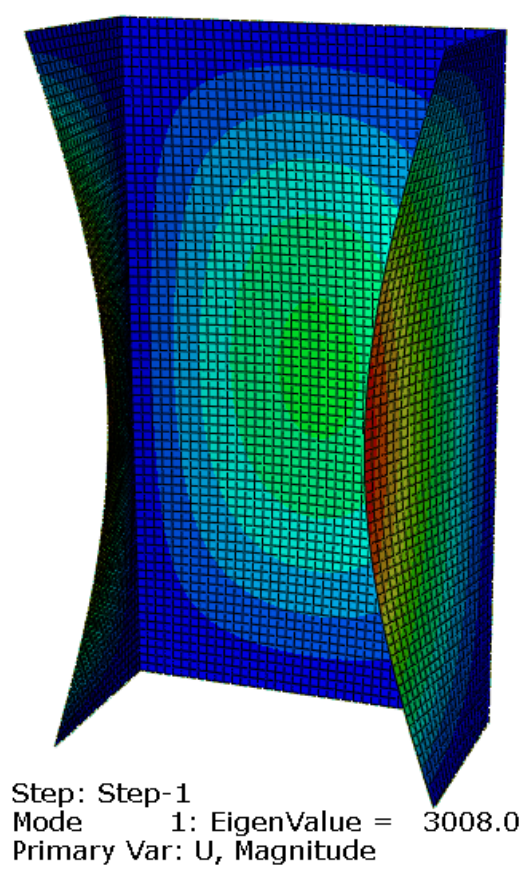

b)

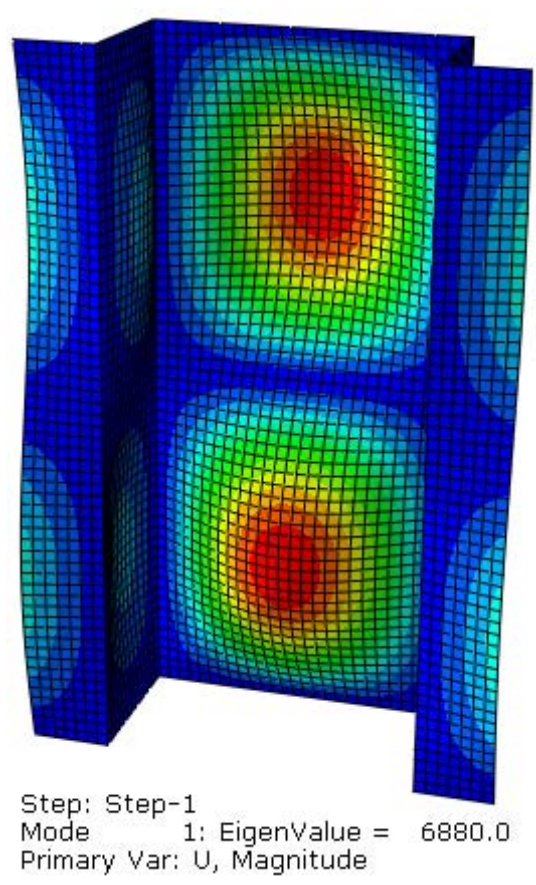

Fig.5. Numerical results of critical loads: a) C-shape profile, b) $\Omega$-shape profile.

a)

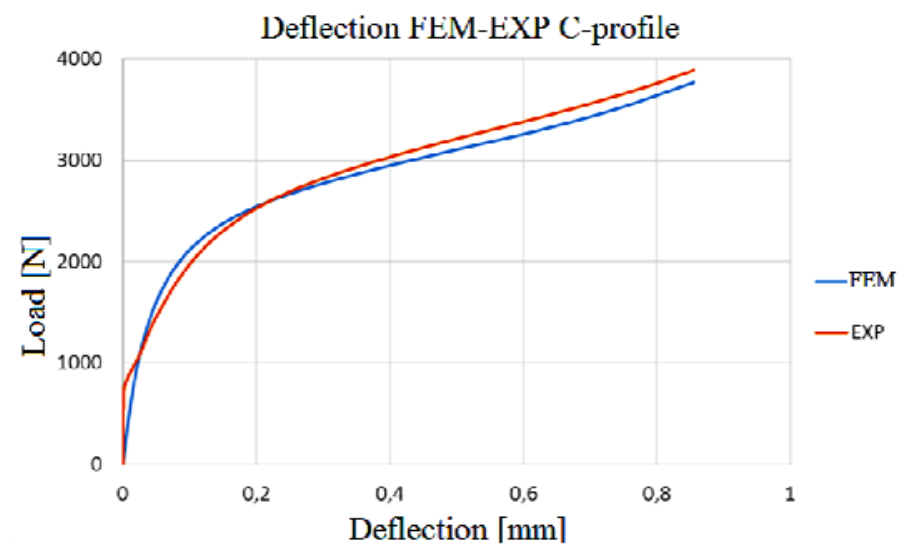

b)

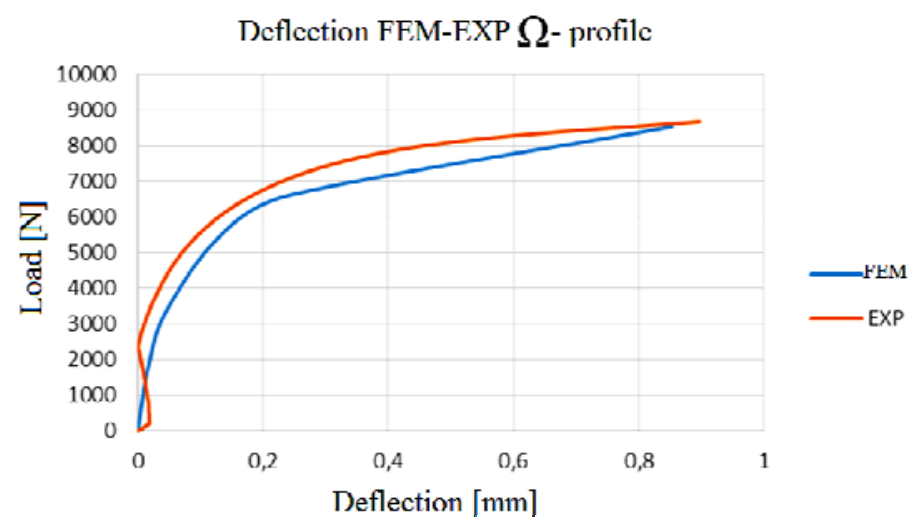

Fig.6. Load vs. deflection: a) C-shape profile, b) $\Omega$-shape profile. 
To obtain accurate results, the FEM analysis was performed for a non-linear numerical problem by the Newton-Raphson method based on an iterative algorithm for determining the approximate values of root function describing a given problem [[35]]. The numerical and experimental results of the critical forces show a very high agreement. In the case of the $\Omega$-shaped section profile, the difference between the FEM calculations and the experiment results is $1.18 \%$ in the first test, $0.33 \%$ in the second test and $0.2 \%$ in the third one. The C-shaped section profile also shows a high agreement of the results, amounting to $5.9 \%$ in the first trial, $3.2 \%$ in the second trial and $0.4 \%$ in the third trial. The next step of the study was to determine the extent of agreement between the numerical and experimental results of the sample's deflection under the applied boundary conditions. This was done by investigating the relationship between load and deflection by FEM and experimental tests. Deflection was attributed to the effect of previously determined critical forces, on the basis of which the expected parameters were adequately defined. The results are given in the figures below.

The results show a high agreement between the numerical and experimental results of load and deflection. The experimental findings differ from the ideal state obtained by the numerical analysis due to geometric imperfections of the real samples and the degree of the boundary conditions mapping. During the loading process the real structure must be matched to the preset boundary conditions on the testing machine, which is the main cause of the differences between the experimental and numerical results.

\section{Conclusions}

The paper investigated the problem of nonlinear stability of thin-walled profiles subjected to axial compression. The numerical results agree with the experimental findings concerning the critical state of the tested structures. Based on the results, one can formulate the following conclusions:

- critical forces can be determined by numerical analysis in relation to the linear eigenvalue problem criterion based on the minimum potential energy of structure,

- the approximation methods allow us to determine values of the critical forces obtained in the experimental tests,

- the numerical and experimental results of critical forces show a high agreement, which demonstrates that the numerical models and the applied methods for defining the critical operating range of the structures were correct,

- the agreement between the numerical and experimental results of load and deflections is due to precise mapping of the boundary conditions complying with the ideal FEM assumptions.

The FEM results have proved to be a useful means of observation and investigation of deformation of thin-walled profiles in a full range of load. Numerical analysis is a powerful tool to study the loadcarrying capacity and effort of thin-walled structures under defined loads.

\section{References}

[1] Bazant Z.P. and Cedolin L. (2010): Stability of Structures. - Elastic, Inelastic, Fracture and Damage Theories. Oxford University Press, UK.

[2] Becque J. and Rasmusen KJR. (2009): Experimental investigation of local-overall interaction buckling of stainless steel lipped channel columns. - J. Constructional Steel Research, vol.65, pp.1677-1684.

[3] Bloom F. and Coffin D. (2001): Handbook of Thin Plate Buckling and Postbuckling. - CHAPMAN AND HALL/CRC Boca Raton, London, New York, Washington, D.C.

[4] Debski H. (2013): Experimental investigation post-buckling behaviour of composite column with top-hat cross section. - Maintenance and Reliability, vol.2, pp.105-109. 
[5] Debski H. and Sadowski T. (2014): Modelling of microcracks initiation and evolution along interfaces of the WC/Co composite by the finite element method. - Computational Materials Science, vol.83, pp.403-411.

[6] Debski H., Teter A., Kubiak T. and Samborski S. (2016): Local buckling, post-buckling and collapse of thinwalled channel section composite columns subjected to quasi-static compression. - Composite Structures; vol.136, pp.593-601.

[7] Debski H., Teter A. and Kubiak T. (2014): Numerical and experimental studies of compressed composite columns with complex open cross-sections. - Composite Structures, vol.118, pp.28-36.

[8] Doyle J.F. (2001): Nonlinear Analysis of Thin-Walled Structures. - Springer.

[9] Falkowicz K., Mazurek P., Rozylo P., Wysmulski P. and Smagowski P. (2016): Experimental and numerical analysis of the compression of a thin-walled composite plate. - Advances in Science and Technology Research Journal, vol.10, No.31, pp.177-184.

[10] Falkowicz K., Ferdynus M. and Dębski H. (2015): Numerical analysis of compressed plates with a cut-out operating in the geometrically nonlinear range. - Maintenance and Reliability, vol.17, No.2, pp.222-227.

[11] Kolakowski Z. and Teter A. (2015): Static interactive buckling of functionally graded columns with closed crosssections subjected to axial compression. - Composite Structures, vol.123, pp.257-262.

[12] Kopecki T. and Mazurek P. (2014): Numerical representation of post-critical deformations in the processes of determining stress distributions in closed multi-segment thin-walled aircraft load-bearing structures. Maintenance and Reliability, vol.16, No.1, pp.164-169.

[13] Kopecki T. and Mazurek P. (2013): Problems of numerical bifurcation reproducing in postcritical deformation states of aircraft structures. - Journal of Theoretical and Applied Mechanics, vol.51, No.4, pp.969-977.

[14] Kubiak T. (2013): Static and Dynamic Buckling of Thin-Walled Plate Structures. - London: Springer, Verlag.

[15] Lonkwic P. and Różyło P. (2016): Theoretical and experimental analysis of loading impact from the progressive gear on the lift braking distance with the use of the free fall method. - Advances in Science and Technology Research Journal, vol.10, No.30, pp.103-109.

[16] Lonkwic P., Różyło P. and Dębski H. (2015): Numerical and experimental analysis of the progressive gear body with the use of finite-element method. - Maintenance and Reliability, vol.17, No.4, pp.544-550.

[17] Magnucka-Blandzi E. and Magnucki K. (2011): Buckling, and optimal design of cold-formed thin-walled beams: Review of selected problems. - Thin-Walled Structures; vol.49, pp.554-61.

[18] Mania R.J., Kolakowski Z., Bienias J., Jakubczak P. and Majerski K. (2015): Comparative study of FML profiles buckling and postbuckling behaviour under axial loading. - Composite Structures, vol.134, pp.216-225.

[19] Parlapalli M.R., Soh K.C., Shu D.W. and Ma G. (2007): Experimental investigation of delamination buckling of stitched composite laminates. - Composites: Part A, vol.38, pp.2024-33.

[20] Paszkiewicz M. and Kubiak T. (2015): Selected problems concerning determination of the buckling load of channel section beams and columns. - Thin-Walled Structures, vol.93, pp.112-121.

[21] Roorda J. (1967): Some thoughts on the Southwell plot. - Proc. ASCE, Journ. of the Engineering Mechanics Division, vol.93, No.EM6.

[22] Rozylo P. (2016): Optimization of I-section profile design by the finite element method. - Advances in Science and Technology Research Journal, vol.10, No.29, pp.52-56.

[23] Rozylo P. and Wrzesinska K. (2016): Numerical analysis of the behavior of compressed thin-walled elements with holes. - Advances in Science and Technology Research Journal, vol.10, No.31, pp.199-206.

[24] Rudawska A. and Debski H. (2011): Experimental and numerical analysis of adhesively bonded aluminium alloy sheets joints. - Maintenance and Reliability, vol.1, pp.4-10.

[25] Singer J., Arbocz J. and Weller T. (1998): Buckling experiments. Experimental methods in buckling of thin-walled structure. - Basic Concepts, Columns, Beams, and Plates, vol.1. New York: John Wiley and Sons Inc.; (vol.2: 2002). 
[26] Teter A., Debski H. and Samborski S. (2014): On buckling collapse and failure analysis of thin-walled composite lipped-channel columns subjected to uniaxial compression. - Thin-Walled Structures, vol.85, pp.324-331.

[27] Teter A. and Kolakowski Z. (2005): Buckling of thin-walled composite structures with intermediate stiffeners. Composite Structures, vol.69, pp.421-428.

[28] Teter A. and Kolakowski Z. (2015): Load carrying capacity of functionally graded columns with open crosssections under static compression. - Composite Structures, vol.129, pp.1-7.

[29] Tereszowski Z. (1970): Experimental method for determining critical loads in plates. - Archive of Mechanical Engineering, T. XVII, No.3, Warsaw.

[30] Turvey G.J. and Zhang Y. (2006): A computational and experimental analysis of the buckling, postbuckling and initial failure of pultruded GRP columns. - Computers and Structures, vol.84, pp.1527-1537.

[31] Van der Heijden A.M.A. (2009): W.T. Koiter's Elastic Stability of Solids and Structured. - Cambridge University Press.

[32] Wong P.M.H. and Wang Y.C. (2007): An experimental study of pultruded glass fibre reinforced plastics channel columns at elevated temperatures. - Composite Structures, vol.81, pp.84-95.

[33] Wysmulski P., Debski H., Rozylo P. and Falkowicz K. (2016): A study of stability and post-critical behaviour of thin walled composite profiles under compression. - Maintenance and Reliability, vol.18, No.4, pp.632-637.

[34] Zaraś J., Królak M. and Kotełko M. (2006): Experimental methods for determining critical loads and analysis of the behavior of construction elements in postbuckling - X National Conference of Strength of Materials and Testing of Materials, Kudowa-Zdrój 20-22 IX.

[35] Zienkiewicz O.C. and Taylor R.L. (2000): Finite Element Method (5th Edition) Volume 2 - Solid Mechanics". Elsevier.

Received: December 18, 2016

Revised: March 30, 2017 